ESSAY REVIEW

\title{
For the Good of Your Health, Read This Book
}

\author{
Danger Within Us: America's Untested, Unregulated Medical De- \\ vice Industry and One Man's Battle to Survive It by Jeanne Lenzer. \\ Little, Brown, 2017. 329 pp. \$28 (hardcover). ISBN 978-0316343763.
}

\author{
Reviewed by Henry H. Bauer \\ Virginia Polytechnic Institute \& State University \\ hhbauer@vt.edu; www.henryhbauer.homestead.com \\ https://10.31275/20201897 \\ Creative Commons License CC-BY-NC
}

Everyone needs to read this book-everyone who may ever be in need of any sort of healthcare in the United States needs to read this book. Doctors should read this book; nurses should read this book; politicians should read this book; lawyers and prosecutors and district attorneys should read this book.

The reason is that healthcare in the United States is the most expensive and least efficient in the developed world, costing twice as much but delivering worse outcomes (on longevity, for instance) than in almost every other developed nation (pp. 12 ff., 58, 59). Dozens of books ${ }^{1}$ and hundreds of articles by well-informed insiders have pointed to flaws in the delivery of healthcare. The circumstances are so nonplanned and dysfunctional that it would even be misleading to speak of a healthcare "system."

Danger Within Us touches on every salient aspect of the dysfunctionality. If you read only one book about what is wrong with modern American medicine, this is the book to read. I marked so many places as worth citing emphatically that it becomes rather easy to give a synopsis of this review: Everyone should read the whole book. 
The problems that plague the medical device industry reveal a troubling pattern of financial kickbacks, perverse incentives, and institutional conflicts that too often give short shrift to the needs and safety of patients. (p. 201)

I was beginning to feel as if I were in a Kafka novel. (p. 187)

The same problems plague everything connected with healthcare in the United States.

The explicit focus in this book is on medical devices that are implanted, for example artificial joints and cardiac pacemakers; and a continuing thread tells the story of one individual whose implanted device came very close to killing him. But in recounting this story, and in discussing issues that affect all types of implanted devices, Jeanne Lenzer touches on all of the things that need to be changed, to be fixed, in current American medical practices.

I read the book just a few pages at a time because the anecdotes are so horrifying that my blood pressure would rise significantly. But these are not "just anecdotes," they are cogent illustrations of the general state of affairs, which is reliably documented in nearly 400 source notes-as indeed one has come to expect from this author. Lenzer has published many important pieces of investigative medical journalism, in particular in BMJ (British Medical Journal). With most nonfiction I often feel it necessary to check the author's statements against cited references or other publications on the topic, but when I read something by Lenzer, I am saved that extra effort because, after checking in earlier pieces by her, I have found her to be scrupulously conscientious and trustworthy.

Perhaps the prime immediate culprit in much of the dysfunctionality of present-day practices is the Food and Drug Administration (FDA). For one thing, its databases of adverse events and deaths are not reliable (pp. 112-114). For another, it accepts results from clinical trials paid for by manufacturers without examining whether the trials were performed properly. Among the consequences is that the number of recalls of medical devices increased from 8 in 2003 to 176 in 2013 (p. 123) —and every recall comes only after a significant number of patients have experienced significant harm. The delay is owing in part to the fact that the FDA does not enforce what are purportedly mandatory 
requirements for monitoring the performances of devices and drugs after they have been approved and marketed.

All too often, recommendations from the FDA's technical staff not to approve something are overruled by management as a result of political influence-what we would unhesitatingly label sheer corruption if it occurred in other countries. Up to 1968, the FDA Commissioner was a civil servant, but since then (courtesy of the Nixon Administration) it has been a political appointment. In effect, the FDA now serves the interests of manufacturers more than of the public. The revolving door between industry and government agencies needs to be closed. Conflicts of interest and political interference have corrupted fatally the work of this agency (p. 130 ff.). That manufacturers pay the FDA the costs connected with approval contributes to the problem; and not only with the FDA: The Centers for Disease Control \& Prevention (CDC) campaigned to promote use of Tamiflu, costs of the campaign being underwritten by the drug's manufacturer, Roche (p. 104). In 2020 , the $C D C$ was vigorously promoting HPV vaccination, whose anticancer efficacy has never been established and whose damaging side effects are (so far) more numerous than for any other vaccine (Holland \& Rosenberg, 2018).

Misguided reliance on the FDA (and the CDC, and other official sources) causes practicing physicians and surgeons not only to harm patients but also sometimes themselves, as with the orthopedic surgeon who suffered badly after being implanted with a metal-on-metal joint that he had come to believe was the best available (191 ff.)-based on his sources of information, the FDA and the sales representatives of the device's manufacturer. He had for some time implanted the same device in patients without suspecting harm-because the harm (metallosis, tissue damage from dissolving metal) comes after an appreciable period of time and was known only to the manufacturer.

Laws concerning healthcare are typically written by lobbyists for manufacturers and rubber-stamped by the Congress-people who ostensibly originate the legislation. One law, for example, prevents people injured by a medical device from suing the manufacturer if the device had been approved by the FDA (p. 117); and misguided approvals are rife. Many individuals have incurred sometimes fatal damage from many devices: artificial cartilage (p. 138 ff.), artificial metal-on-metal 
hips (p. 192 ff.), birth-control electrical devices (p. 110) and "shields" (p. 119), defibrillators, stents, vagus-nerve stimulators, and more.

A common strategy used by manufacturers is to create foundations or groups that claim to speak on behalf of the interests of patients when they are actually mouthpieces for the manufacturers (pp. 157158); and the drug companies use these deceptive mouthpieces when petitioning the FDA for approval or when defending lawsuits or trying to spin the media.

The lack of careful regulation, and its corruption by political influences, have led to dishonest practices becoming standard procedure. Too many clinical trials, paid for and controlled by drug companies, are deliberately corrupted, which is easily done in a variety of ways: inappropriate controls, inappropriate sampling of patient and control populations, inappropriate statistical analyses; by 2014, $86 \%$ of clinical trials were being funded by industry (p. 238). Sales representatives, under explicit or implicit direction by their company, routinely break the law by encouraging doctors to prescribe drugs or devices for off-label uses. ${ }^{2}$ Almost every major drug and medical device company has been caught in at least one scandal, and massive fines, often billions of dollars, have become an accepted part of their normal cost of doing business (p. 17). The detailed stories of Cyberonics (passim), Medtronic, and Johnson \& Johnson (p. 146 ff.) illustrate that merely finding companies at fault and imposing fines does not stop the criminal practices; instead, decisionmakers in the companies need to suffer the consequences personally.

There exists, in other words, a little-recognized medical-industrial complex no less dangerous to society at large than is the well-recognized military-industrial complex. Neither has been successfully tamed or harnessed, and the medical one is daily damaging a significant number of people.

Regulation is hindered not only by practical considerations of political influence and unbridled greed but also by the inevitable lack of certainty in trying to understand human physiology and behavior. A fundamental difficulty is that individuals react in different ways to a given stimulus, and what may help one person at a given time is not necessarily the best general treatment for everyone. So it can happen that treatments long regarded as standard and routine may actually do 
more damage overall than could be justified by their benefits. Lenzer learned this at first hand when she worked as a physician assistant: Premature ventricular contractions (PVCs) had been treated routinely by certain drugs, and many physicians had seen, as Lenzer had herself, that these drugs could very effectively prevent atrial fibrillation. So Lenzer was "devastated," she writes (p. 5), when finally a properly large and controlled clinical trial found that these drugs could indeed prevent fibrillation but they also increase mortality by a significant amount (3.6-fold).

\section{DANGER}

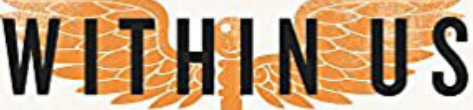

AMERICA'S UNTESTED,

UNREGULATED MEDICAL

DEVICE INDUSTRY

ANO ONE MAN'S BATTLE

TO SURVIVE IT

\section{JEANNE LENZER}

The not-well-known, disconcerting, fact is that medical devicesand also drugs-"can sometimes cause the very symptoms they are intended to cure" (p. 6). The best of intentions may also bring unintended harmful consequences; thus the 1980 Bayh-Dole Act (p. 238 ff.) was intended to encourage technology transfer from academe to the marketplace for better and more rapid availability of medical advances and to allow academe to share in the profits from its discoveries; instead, it has led to pervasive conflicts of interest, institutional and personal, and the inevitably associated corruption.

An inherent barrier to achieving certainty in medicine is that experiments or observations cannot always be carried on long enough for outcomes to become obvious. Therefore, clinical trials very often measure only so-called surrogate markers that are taken to be satisfactory predictors of outcomes; for instance, blood pressure as one indicator of cardiovascular disease. All too often, however, surrogate markers can be misleading, ${ }^{3}$ for example with stents (p. 77 ff.). A surrogate marker can make a device seem beneficial even when it actually causes harm (p. 187).

The problem of getting reliable information about medical 
treatments is owing in part to randomness because many variables usually contribute to any particular state of illness or health; any observation might be highly favorable (or unfavorable) purely by chance, but eventually, as in a properly long trial, such misleading outliers will regress to the mean, as is well known to professional statisticians but not necessarily to others. Again, the placebo effect ${ }^{4}$ (Harrington, 1997; Shapiro \& Shapiro, 1997) can cause patients to deliver misleading reports about changes in their symptoms. A common danger is that physicians and nurses are naturally predisposed to believe that the remedies they prescribe and supervise can only be of benefit; so when a drug or a device causes something that mimics the ailment being treated, that harmful side effect is rarely recognized (p. 173).

Incompetent or deliberately misleading statistical reports are rife in medical matters. It is not usually emphasized, for example, that statistical significance is an arbitrary criterion and does not constitute proof of anything. The most meaningful measure is very often all-cause morbidity or mortality, but that is usually not reported-because to do so would reveal the tested treatment as having little or no benefit. It is not mentioned in this book, but the most useful data from a patient's point of view are NNH and NNT: number of patients needed to be treated so that one of them is likely to be harmed and number of patients needed to be treated so that one is likely to benefit; one wants $\mathrm{NNH}$ to be much larger than NNT.

Revealing scandalous corruption and incompetence is not this book's only service to readers, it also offers much intrinsically interesting information: about the origin and development of the FDA (p. 101 ff.), for instance. And that there are risks that few people would conceive of: Some implanted medical devices_-pacemakers, for example-are conveniently fitted with Wi-Fi capability so they can be monitored and programmed without surgery; but such devices are thereby also, like everything on the Internet, at the mercy of hackers. And how would you know, without reading this book, that intractable hiccups can be cured by wiggling a finger in the rectum (p. 72)?

Extremely useful also are pages 284-289 listing industryindependent organizations, publications, and patient advocacy and support groups; as well as for journalists in particular, a periodically 
updated list, available online, of international industry-independent experts.

The concluding chapter of Danger Within Us has the title, "What is to be done?" Unfortunately, it gives little ground for optimism. Lenzer remarks on growing grassroots initiatives such as the Right Care Alliance, and certainly this is grounds for optimism—albeit only in the long run. She is also quite right that the United States needs a singlepayer health system; and that the patent system needs to be reformed; and that the FDA needs to do what it is charged to do but presently does not, namely, approve new or modified medical devices (and of course drugs, too) only after they have been found to be both safe and effective in clinical trials administered by properly conscientious and independent investigators. The problem is that none of those things are likely to happen until there is thoroughgoing reform of the way in which political campaigns are being financed; under current circumstances, everything to do with healthcare is controlled by the pharmaceutical industry.

Lenzer understands that perfectly well: "There is no conspiracy in any of this-just a confluence of interests that stretches across the entire healthcare industry" (p. 225).

We are fortunate to have any number of competent and idealistic doctors, nurses, and aides; but they are hindered in caring for their clients and patients by restrictions imposed by the for-profit institutions that dominate all healthcare. Pharmaceutical companies are at the forefront in putting profits ahead of everything else, but for-profit hospitals and purportedly nonprofit healthcare systems are not far behind (p. 14) since practices are dominated by the for-profit institutions, and no organization can long exist if it loses money all the time. That is why a single-payer system is needed. Maintaining national defense, an inevitably very expensive system of armed forces, requires a national single-payer system because even the most efficient competitive free market could not be relied on to do the job; so too with maintaining the nation's health. Both are essential for the wellbeing of every individual in the nation and neither could be supplied equitably and reliably through a private, free-market system. 


\section{NOTES}

${ }^{1}$ An occasionally updated bibliography of almost 100 books and a few salient articles are available at https://mega.nz/file/ZLhyGSxY\#t2wneBEy HdMpDU 57 Lcej95MJerV7BUykQ23BpFRya6vl

${ }^{2}$ It is legal for doctors to prescribe for any condition at all any drug or device once it has been FDA-approved for anything. But it is illegal to advertise or promote a drug or device for off-label use.

3 See two reports from the Institute of Medicine: Evaluation of Biomarkers and Surrogate Endpoints in Chronic Disease and Perspectives on Biomarker and Surrogate Endpoint Evaluation: Discussion Forum Summary, National Academies Press, 2010 and 2011.

${ }^{4}$ One of the remarkable characteristics of the placebo effect is that it works even when one knows that a placebo is being administered; presumably the subconscious mind does its powerful work in any case. For several decades I had a wonderfully empathetic physician; it had become a happily shared insight that he exerted on me a strong placebo effect: My belief in his expert care caused me to feel better after my visit, no matter how physically ill I might nevertheless be.

\section{REFERENCES}

Harrington A. (Ed.). (1997). The placebo effect-An interdisciplinary exploration. Harvard University Press.

Holland, M., \& Rosenberg, K. M. (2018). The HPV vaccine on trial: Seeking justice for a generation betrayed. Skyhorse.

Shapiro, A. K., \& Shapiro E. (1997). The powerful placebo-From ancient priest to modern physician. Johns Hopkins University Press. 